\title{
Title: Ancient microRNA profiles of a 14,300-year-old canid are taxonomically informative and give glimpses into gene regulation from the Pleistocene
}

Authors: $\quad$ Bastian Fromm1*, Marcel Tarbier1, Oliver Smith2,3, Love Dalén4,5, M. T. P. Gilbert2,5, Marc R. Friedländer1*

\section{Affiliations:}

1 Science for Life Laboratory, Department of Molecular Biosciences, The Wenner-Gren Institute, Stockholm University, Stockholm, Sweden

2 Section for Evolutionary Genomics, The Globe Institute, Faculty of Health and Medical Sciences, University of Copenhagen, Copenhagen, Denmark

3 Micropathology Ltd, Venture Centre, University of Warwick Science Park, Coventry, UK

4 Centre for Palaeogenetics, Svante Arrhenius väg 20C, Stockholm, Sweden

5 Department of Bioinformatics and Genetics, Swedish Museum of Natural History, SE-10405 Stockholm, Sweden

6 Norwegian University of Science and Technology, University Museum, Trondheim, Norway

*_corresponding authors: bastianfromm@gmail.com \& marc.friedlander@scilifelab.se 


\begin{abstract}
Ancient DNA sequencing is the key technology for paleogenomic studies and today a routine method in many laboratories. Recent analyses have shown that, under favoring conditions, also RNA can be sequenced from historical and even ancient samples. We have re-analyzed ancient RNA data from a Pleistocene canid and find - in addition to the previously described messenger RNA fragments - intact microRNAs, which are short transcripts with important gene regulatory functions. With an extraordinary age of 14,300 years, the canid microRNA profiles are the oldest ever reported. Despite their age, we show that the microRNA profiles are conclusive of taxonomic origin, tissue identity with organ- and cell-type specific signatures, and that they yield glimpses into gene regulatory activity and biological processes from the Pleistocene. In summary, we here show that straightforward microRNA analyses hold great promise for deeper insights into gene regulation in extinct animals.
\end{abstract}




\section{Introduction}

Sequencing historic and ancient DNA from up to 600,000-year-old samples has become a standard approach to infer the genetic history of extinct or extant species (Orlando et al. 2013). While much has been learned from studying these genomes, it remains difficult to infer cellular processes, such as in vivo genome function, from DNA directly.

In contrast, RNA conveys genetic information at the functional level, and can thus give insights into the biological activity, the tissue identity, or even the cellular composition of samples (Newman et al. 2015). However, based on a putative relative lack of surviving material in historic and ancient samples, due to the release of RNases during decomposition in most tissues (Huynen et al. 2012), 'ancient RNA' (aRNA) has rarely been studied and is often disregarded as a source for biological discoveries. On the other hand, preservative conditions for aDNA (cold, draught) actually also inhibit RNAses, and there are significantly more RNA molecules than DNA found per cell (see for microRNA (Calabrese et al. 2007)).

With the availability of powerful and sensitive sequencing approaches, a small number of recent studies have capitalised on early observations of very short RNA fragments surviving in some archaeological plant and mummified materials (Rollo 1985; Venanzi and Rollo 1990), and have recovered sequenceable amounts of aRNA from historic plant and feces samples. In doing so they have detected, for instance, viral RNA genomes (Ng et al. 2014; Smith et al. 2014), microRNAs (Smith et al. 2017) and even fragments of protein-coding transcripts (Fordyce et al. 2013). While these studies represent a proof of concept for aRNA sequencing, or paleotranscriptomics, they are limited to relatively recent ( $<1000$ years old) samples and, except for one study, restricted on seedmaterial that conveys highly preservative conditions. 
A recent sequencing study on three permafrost and two historical canid samples showed that aRNA can survive for extended periods in mammalian samples (Smith et al. 2019). With approximately 14,300 years of age for the Pleistocene permafrost samples, the authors presented the oldest ever sequenced RNA to date. In a paleotranscriptomic analysis, using two custom bioinformatics methods based on total aRNA profile comparisons to recent tissue sample profiles, aRNA profiles could resolve tissue identity for two of the samples.

Because the applied sequencing strategy (single-end, short read, without size-selection) clearly favors short RNAs, we here investigate whether microRNAs can also be identified in the data. MicroRNAs are 22 nucleotide short RNA molecules that are excellent cell- and tissue markers (Christodoulou et al. 2010; McCall et al. 2017; de Rie et al. 2017), and stable in historic samples (Keller et al. 2017; Smith et al. 2017). They are produced when RNA hairpin structures ('precursor microRNAs') are cleaved into functional regulatory molecules ('mature microRNAs') and biogenesis by-products ('star microRNAs'). The mature microRNAs are key regulators of protein coding genes with important functions in numerous biological processes including development and disease (Bartel 2018). They are the most conserved elements in metazoan genomes and have great potential as phylogenetic markers (Sempere et al. 2006; Tarver et al. 2013). We have recently curated the microRNA complements of 45 Metazoan organisms, including canid, in the MirGeneDB database (Fromm et al. 2019) and shown that species-specific microRNAs can be used to trace the taxonomic origin of samples using our straightforward software miRTrace (Kang et al. 2018). We here leverage these two resources to characterize the microRNA complements of the ancient and historic canid samples. 


\section{Results}

\section{Abundant microRNA detection in ancient and historic samples}

Reanalyzing the RNAseq datasets (Illumina) for the ancient and historic samples from Smith et al. (Smith et al. 2019), we detected 334 microRNAs (236 mature and 98 star) out of the 447 currently annotated canid microRNAs (Fromm et al. 2019) (Figure 1A), with in total more than 18,000 sequence read-outs, or 'reads', among all samples (Figure 1B). Interestingly, the ratio between detected distinct 'mature' and 'star' products was relatively constant between samples (ranging from 2.3 in ancient liver to 3.0 historic skin samples), suggesting that the two types of molecules are equally affected by time, when preserved in permafrost. Analyses on previously reported damage patterns on aRNA showed comparable patterns in microRNAs (Jónsson et al. 2013; Smith et al. 2019) (Supplementary Figure 1). The overall high number of detected mature and star microRNAs and reads, representing $50 \%$ of all currently known canid microRNAs, was highest for the historic samples and lower for the ancient samples (Figure 1B and 1C). Among the ancient samples, the liver showed the best preservation, which is in line with experimentally observed postmortem migration patterns of bacteria, that showed near-sterile conditions in liver up to 5 days postmortem, which clearly is a reasonable timescale for the Tumat puppy to be frozen (Tuomisto et al. 2013). 


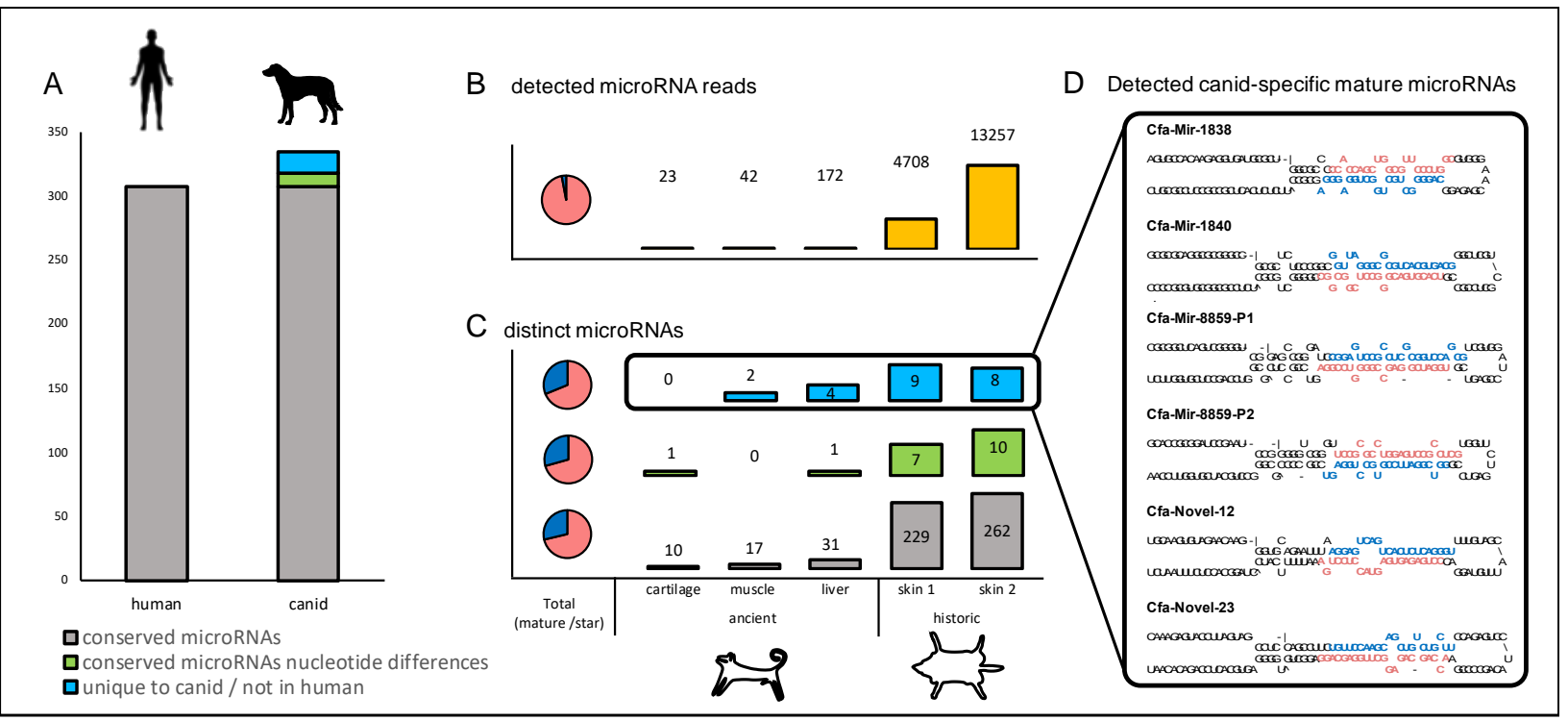

Figure 1: Abundant numbers of conserved and dog-specific microRNAs are detected in historic and ancient samples. A) 334 microRNAs (236 mature and 98 star) are detected in the historic and dog samples, of those 307 microRNAs (219 mature and 88 star) are identical in sequence to human (grey), 11 microRNAs (6 mature and 5 star) show single nucleotide differences (polymorphic) (green) and 16 microRNAs (11 mature and 5 star) are absent in human (blue). B) Total number of microRNA reads detected in each sample (yellow). C) Detailed numbers of conserved, polymorphic and canid-specific microRNAs detected in the 5 ancient and historic samples. D) Hairpin structures and indication of mature (red) and star (blue) products of 6 of the 11 microRNAs not found in human that are specific to canid and currently not known in any other organism.

\section{microRNAs support taxonomic origin of the sequences}

Given the extreme age of the canid aRNA samples, it is a concern that the detected sequences do not originate from the ancient tissues, but rather from trace levels of contamination. Using a large range of species- and clade-specific microRNAs as reference, our software miRTrace did not identify any microRNA-based contamination by non-canid eukaryotes (Supplementary File 1). However, during evolution, the majority of microRNAs are highly conserved in sequence (Fromm et al. 2015; Bartel 2018), and it is important to investigate if the sequences of the detected microRNAs can be used to unambiguously identify the taxonomic species of a sample. The accurate annotations of MirGeneDB enabled us to make sequence comparisons for each microRNA to human and canid, and test for conservation and variation in the 334 individual microRNAs (236 mature and 98 star). 
As expected, we found that the majority of detected microRNAs, in total 307 microRNAs (219 mature and 88 star) belongs to microRNAs that are conserved between human and canid. Thus, these microRNAs are not informative for species delimitation, and, at least theoretically, could derive from contaminations. This is, however, unlikely given the absence of any microRNAs specific to other clades, as shown in the miRTrace analysis.

A canid origin of the sequences was supported by 11 distinct microRNAs (6 mature and 5 star) that showed clear nucleotide differences to their orthologues in human ('polymorphic microRNAs'). The six mature microRNAs also showed differences to other organisms, none of which can be explained by deamination events (C->U conversions; Mir-8-P3a, Mir-28-P2, Mir154-P2, Mir-339, Mir-193-P1b and Mir-105-P2; Supplementary File 2, Supplementary Figure 2B).

Finally, we found 16 microRNAs (11 mature and 5 star) that are present in canid but completely absent in human ('microRNAs unique to canid'). Importantly, 6 of the 11 mature and 3 of the 5 star microRNAs were also not found in other MirGeneDB species and appears to be truly canidspecific, having never evolved in any other animal group (Mir-8859-P1 and P2, Mir-Novel-23, Mir-Novel-12, Mir-1838 and Mir-1840; Figure 1D). This not only renders them candidate biomarkers for the authenticity of the sample (Figure 1C, D), but also makes them stand out as interesting regulatory molecules with putative canid-specific functions. The remaining seven microRNAs ( 5 mature, 2 stars) were not found in human, but were found in other organisms. Of those, single nucleotide differences to at least one or several other species orthologous sequences were found in five microRNAs (Mir-1842, Mir-154-P34, Mir-1388, Mir-2387, and Mir-7180; Supplementary Figure 2A), making them informative for a distinction with canid, too. 
When comparing the levels of detected conserved, polymorphic and unique microRNAs, we saw that not only the historic samples, but also the ancient samples showed all three categories of microRNAs, supporting the authenticity of the microRNA reads (Figure 1C). Altogether, the identification of canid-specific microRNAs and canid-specific microRNA variants strongly supports the authenticity of the sequencing data and provides evidence that no contaminations from closely related species confound our results.

\section{microRNAs inform about cellular and tissue identity of ancient and historic samples}

For extant organisms, it was shown that a number of microRNAs have clear tissue- and sometimes even cell-type specific expression patterns (Christodoulou et al. 2010; McCall et al. 2017; de Rie et al. 2017). In addition, using involved and custom methods, Smith et al. 2019 demonstrated that total aRNA could be used to confirm the identity of ancient liver and one of the historic skin samples (Smith et al. 2019). Therefore, we next asked whether the tissue identity of the samples could be inferred based on the microRNAs as well.

When looking at the top 5 expressed microRNAs of each sample alone, clear signals of tissue and cell-type specific microRNAs were identified. Specifically, we identified Mir-205-P1, a skin and cartilage specific microRNA, as the microRNA with highest abundance in both skin samples and ancient cartilage and Mir-203, with similar tissue specificity, in both historic skin samples (Teta et al. 2012). The 'myoMir' Mir-133 (Sempere et al. 2004) was found among the top 5 microRNAs in the ancient muscle sample, and the hepatocyte-specific Mir-122 (McCall et al. 2017) was among the top 5 microRNAs in the ancient liver, again confirming the identity of these tissues using microRNAs as markers. 
Interestingly, we also noticed relatively high levels of microRNAs that are not strictly specific to any of the tissues (cartilage, muscle, liver and skin), but are known to be specific to range of immune-cells (Table 1). Most notably, the lymphocyte-specific microRNA Mir-155 was detected in all samples and the highest overall detected microRNA in ancient muscle. Mir-148-P1, which is mast-cell specific was detected in all but ancient muscle samples and highest in the ancient liver sample. The high level of these microRNAs suggests a high number of immune-cells in the samples.

Table 1: The relative rank of immune-cell specific microRNAs detected in ancient and historic canid samples. Average ranks were computed for each sample independently. The lower the number, the higher the rank.

\begin{tabular}{l|l|ccccc} 
microRNA & cell-type & $\mathrm{aCa}$ & $\mathrm{aMu}$ & $\mathrm{aLi}$ & $\mathrm{hS} 1$ & $\mathrm{hS2}$ \\
\hline Mir-155 & Lymphocytes & 7 & 1 & 37 & 77 & 67 \\
Mir-339 & Macrophages & - & - & 7 & 45 & 19 \\
Mir-148-P1 & Mast-cells & 7 & - & 1 & 6 & 14 \\
Mir-378 & Dendritic cells & - & 3 & 2 & 3 & 6 \\
Mir-24 & Macrophages & - & 3 & - & 8 & 6
\end{tabular}

Next, we compared the five samples with more than 69 smallRNAseq datasets of fresh soft dog tissues from two previously published studies (Koenig et al. 2016; Penso-Dolfin et al. 2016) using MirGeneDB 2.0 annotations (Fromm et al. 2019). In a principal component analysis (PCA), based on the normalized counts of microRNA sequence reads only, we found that recent samples cluster well according to tissue and organ group (Figure 2). Two of the ancient samples, 'ancient cartilage' and 'ancient muscle', which were previously also shown to have the weakest tissue identity signal 
based on a customized total aRNA analyses (Smith et al. 2019), showed less than 20 expressed distinct microRNAs, with less than 100 microRNA reads in total and did not yield enough information to be included in the PCA. However, the ancient liver sample and the two historic skin samples, clustered well with recent liver and skin samples, respectively (Figure 2).

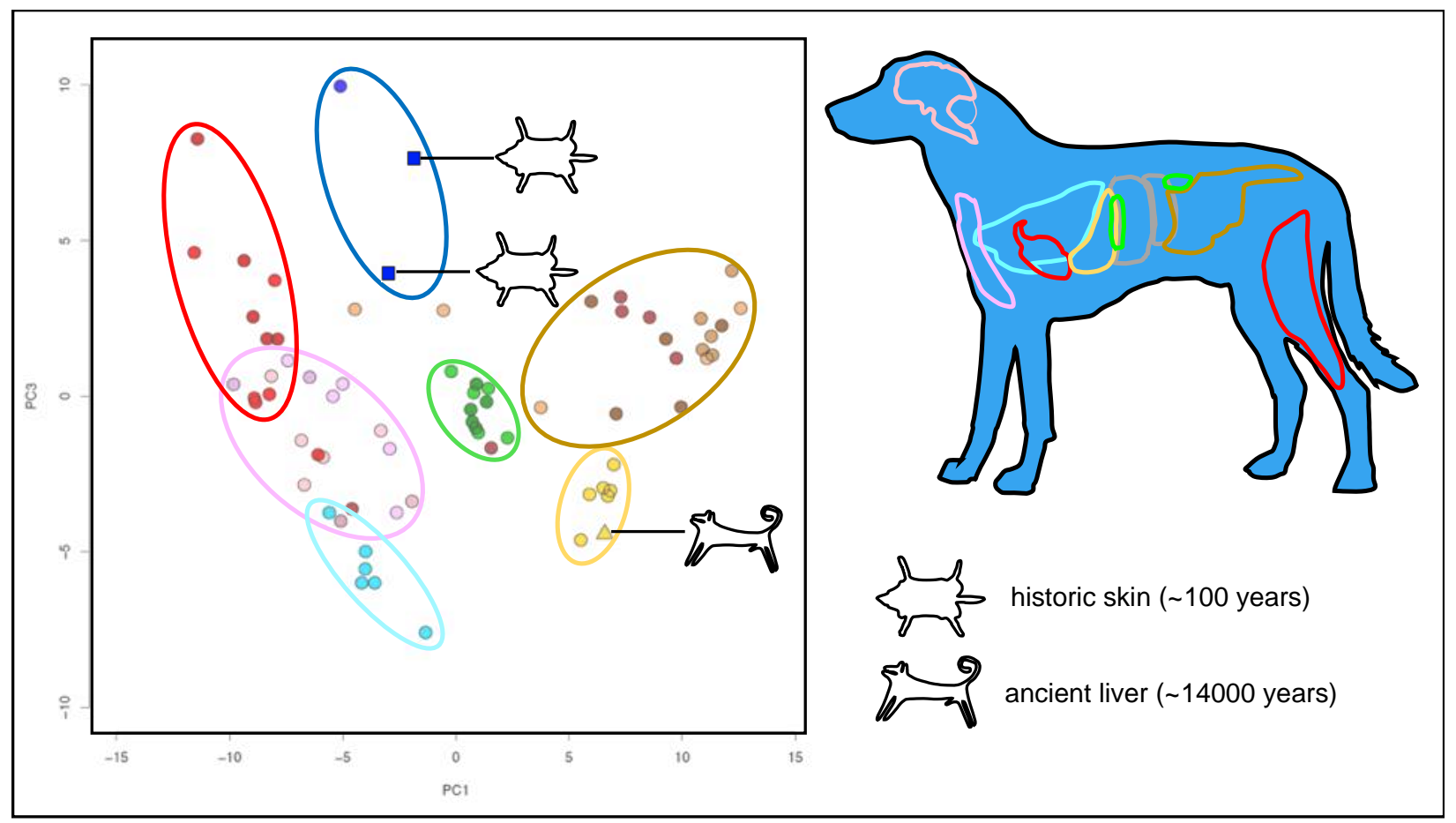

Figure 2: MicroRNA profiles of ancient and historic samples resemble recent tissue expression and are informative for tissue identity. PCA plot of in total 72 samples (69 recent, 1 ancient, 2 historic) show clustering of major organ groups (red - muscle/heart, pink - thymus and brain, light blue - lung, green - kidney and pancreas, dark blue - skin, brown - gastrointestinal tract, yellow - liver). Historic skin samples (dark blue squares) cluster with recent skin samples and the ancient liver sample (yellow triangle) clusters with recent liver samples.

\section{A glimpse into ancient genome activity through microRNAs}

As microRNA themselves are active regulatory molecules, their presence and differential abundance in different tissues alone can directly provide insights into gene regulatory activity (Bartel 2018). Indeed, when we studied the annotated functions of the predicted canid mRNA targets of the tissue-specific microRNAs, we found enrichment for functional annotations 
corresponding to biological processes clearly related to the respective tissue origin. For instance, the predicted targets of Mir-203, which is highly abundant in the historic skin samples, are enriched for the gene ontology "Epithelium and blood vessel development", which is clearly skin related. Similarly, were the targets of Mir-122, which is abundant in ancient liver samples, enriched for "carbohydrate metabolism" and "response to starvation", representing well-established liver functions. Ancient cartilage-specific Mir-205-P1 targets genes that are enriched for "Plateletderived growth factor receptor", which has been described to regulate chondrocyte proliferation (Kieswetter et al. 1997), and the ancient muscle specific Mir-133 targets genes enriched for ontologies related to muscle contraction ("Divalent inorganic cation transmembrane transporter activity") and neuro-transmitters (“GABA receptor binding”). A full list of all specific microRNA and the enrichment of functional annotations within their target gene populations can be found in Supplementary Table 1 . The intriguing distribution of some cell-type specific microRNAs across all samples can be found in Supplementary Figure 3. 


\section{Discussion}

With an estimated age of 14,300 years, we here present the oldest microRNA sequences to date. We report an abundant variety of microRNAs in three ancient and two historic samples and find that the microRNA profiles are informative and conclusive of taxonomic origin for all samples. We further show their ability to identify not only tissue-origin of all samples, but also, to some extent, the likely cellular composition of our samples, including an intriguing signal for high numbers of immune-cells in the sample. These findings encouraged us to ask more functional questions that might help us to get insights or glimpses into the in vivo genome activity of extinct animals. By predicting the targets of the top microRNAs in the samples, we could indeed identify pathways and cellular processes that the samples were likely conducting, and the microRNAs were regulating, 14,300 years ago.

In comparison to analyses of ancient mRNA, microRNA analysis is straight-forward, requiring only simple sequence matching that can be performed without mapping to a reference genome. Further, because microRNAs are captured with protocols that are optimized for highly degraded and fragmented RNA, microRNA analysis could be used as an alternative paleotranscriptomic approach to aRNA data in general. Importantly, since both mature and star sequences are detected well, it would in principle be possible to reliably predict microRNAs de novo in extinct species, possibly discovering novel microRNA families that are not present in any living animals (Ambros et al. 2003; Friedländer et al. 2008; Fromm 2016).

The detection of abundant numbers of intact microRNAs in pleistocene permafrost samples represents a proof of concept and opens up novel opportunities for future studies on the in vivo genome activity in other ancient samples, in particular those from extinct animals such as mammoths, cave lions and others that the increasingly melting permafrost might provide. 


\section{Materials and Methods}

Briefly, Illumina samples from ancient and historic (Smith et al. 2019) as well as fresh tissues (Koenig et al. 2016; Penso-Dolfin et al. 2016) were downloaded from SRA using sra-toolkit 2.9.2 (Leinonen et al. 2010), processed using miRTrace (Kang et al. 2018) and quantified using the 'quantify' function of miRDeep2 (Friedländer et al. 2012) with the MirGeneDB 2.0 dog microRNA complement as reference (Fromm et al. 2019). Sequence comparisons to human and other vertebrate microRNA complements are based on MirGeneDB 2.0 annotations (Fromm et al. 2019) and the consistent nomenclature of microRNA gene orthologues, paralogues and families (Fromm et al. 2015). Alignments were checked using custom scripts and AliView alignment viewer (Larsson 2014).

PCA analyses were based on ubiquitously expressed microRNAs (more than $95 \%$ of all samples, and ancient liver) on all tissue samples, excluding ancient cartilage and ancient muscle, bone marrow and sexual organs such as testis and ovary.

Tissue-specific microRNA were defined as those that are abundant in the tissues of interest but not abundant in other tissues included in this study. Targets of these microRNA were downloaded from TargetScanHuman using the lift over to dog transcripts. Gene ontology and KEGG pathway enrichment analysis were performed on the top 400 targets of these microRNA using the R packages topGO and clusterProfiler. Relevant annotations were selected from the (up to) 25 highest ranking significant terms. 


\section{References}

Ambros V, Bartel B, Bartel DP, Burge CB, Carrington JC, Chen X, Dreyfuss G, Eddy SR, Griffiths-Jones S, Marshall M, et al. 2003. A uniform system for microRNA annotation. RNA 9:277-279.

Bartel DP. 2018. Metazoan MicroRNAs. Cell 173:20-51.

Calabrese JM, Seila AC, Yeo GW, Sharp PA. 2007. RNA sequence analysis defines Dicer's role in mouse embryonic stem cells. Proc. Natl. Acad. Sci. U. S. A. 104:18097-18102.

Christodoulou F, Raible F, Tomer R, Simakov O, Trachana K, Klaus S, Snyman H, Hannon GJ, Bork P, Arendt D. 2010. Ancient animal microRNAs and the evolution of tissue identity. Nature 463:1084-1088.

Fordyce SL, Ávila-Arcos MC, Rasmussen M, Cappellini E, Romero-Navarro JA, Wales N, Alquezar-Planas DE, Penfield S, Brown TA, Vielle-Calzada J-P, et al. 2013. Deep sequencing of RNA from ancient maize kernels. PLoS One 8:e50961.

Friedländer MR, Chen W, Adamidi C, Maaskola J, Einspanier R, Knespel S, Rajewsky N. 2008. Discovering microRNAs from deep sequencing data using miRDeep. Nat. Biotechnol. 26:407-415.

Friedländer MR, Mackowiak SD, Li N, Chen W, Rajewsky N. 2012. miRDeep2 accurately identifies known and hundreds of novel microRNA genes in seven animal clades. Nucleic Acids Res. 40:37-52.

Fromm B. 2016. microRNA discovery and expression analysis in animals. In: Field guidelines for genetic experimental designs in high-throughput sequencing. Springer, Cham. p. 121142.

Fromm B, Billipp T, Peck LE, Johansen M, Tarver JE, King BL, Newcomb JM, Sempere LF, Flatmark K, Hovig E, et al. 2015. A Uniform System for the Annotation of Vertebrate microRNA Genes and the Evolution of the Human microRNAome. Annu. Rev. Genet. 49:213-242.

Fromm B, Domanska D, Høye E, Ovchinnikov V, Kang W, Aparicio-Puerta E, Johansen M, Flatmark K, Mathelier A, Hovig E, et al. 2019. MirGeneDB 2.0: the metazoan microRNA complement. Nucleic Acids Res. [Internet]. Available from: http://dx.doi.org/10.1093/nar/gkz1016

Huynen L, Millar CD, Lambert DM. 2012. Resurrecting ancient animal genomes: the extinct moa and more. Bioessays 34:661-669.

Jónsson H, Ginolhac A, Schubert M, Johnson PLF, Orlando L. 2013. mapDamage2.0: fast approximate Bayesian estimates of ancient DNA damage parameters. Bioinformatics 29:1682-1684. 
Kang W, Eldfjell Y, Fromm B, Estivill X, Biryukova I, Friedländer MR. 2018. miRTrace reveals the organismal origins of microRNA sequencing data. Genome Biol. 19:213.

Keller A, Kreis S, Leidinger P, Maixner F, Ludwig N, Backes C, Galata V, Guerriero G, Fehlmann T, Franke A, et al. 2017. miRNAs in Ancient Tissue Specimens of the Tyrolean Iceman. Mol. Biol. Evol. 34:793-801.

Kieswetter K, Schwartz Z, Alderete M, Dean DD, Boyan BD. 1997. Platelet derived growth factor stimulates chondrocyte proliferation but prevents endochondral maturation. Endocrine 6:257-264.

Koenig EM, Fisher C, Bernard H, Wolenski FS, Gerrein J, Carsillo M, Gallacher M, Tse A, Peters R, Smith A, et al. 2016. The beagle dog MicroRNA tissue atlas: identifying translatable biomarkers of organ toxicity. BMC Genomics 17:649.

Larsson A. 2014. AliView: a fast and lightweight alignment viewer and editor for large datasets. Bioinformatics 30:3276-3278.

Lee M, Kim B, Kim VN. 2014. Emerging Roles of RNA Modification: m6A and U-Tail. Cell 158:980-987.

Leinonen R, Sugawara H, Shumway M, Collaboration INSD. 2010. The sequence read archive. Nucleic Acids Res. 39:D19-D21.

McCall MN, Kim MS, Adil M, Patil AH, Lu Y, Mitchell CJ, Leal-Rojas P, Xu J, Kumar M, Dawson VL, et al. 2017. Toward the human cellular microRNAome. Genome Res. 27:1769-1781.

Newman AM, Liu CL, Green MR, Gentles AJ, Feng W, Xu Y, Hoang CD, Diehn M, Alizadeh AA. 2015. Robust enumeration of cell subsets from tissue expression profiles. Nat. Methods $12: 453-457$.

Ng TFF, Chen L-F, Zhou Y, Shapiro B, Stiller M, Heintzman PD, Varsani A, Kondov NO, Wong W, Deng X, et al. 2014. Preservation of viral genomes in 700-y-old caribou feces from a subarctic ice patch. Proc. Natl. Acad. Sci. U. S. A. 111:16842-16847.

Orlando L, Ginolhac A, Zhang G, Froese D, Albrechtsen A, Stiller M, Schubert M, Cappellini E, Petersen B, Moltke I, et al. 2013. Recalibrating Equus evolution using the genome sequence of an early Middle Pleistocene horse. Nature 499:74-78.

Penso-Dolfin L, Swofford R, Johnson J, Alföldi J, Lindblad-Toh K, Swarbreck D, Moxon S, Di Palma F. 2016. An Improved microRNA Annotation of the Canine Genome. PLoS One 11:e0153453.

de Rie D, Abugessaisa I, Alam T, Arner E, Arner P, Ashoor H, Åström G, Babina M, Bertin N, Burroughs AM, et al. 2017. An integrated expression atlas of miRNAs and their promoters in human and mouse. Nat. Biotechnol. 35:872-878. 
Rollo F. 1985. Characterisation by molecular hybridization of RNA fragments isolated from ancient (1400 B.C.) seeds. Theor. Appl. Genet. 71.

Sempere LF, Cole CN, McPeek MA, Peterson KJ. 2006. The phylogenetic distribution of metazoan microRNAs: insights into evolutionary complexity and constraint. J. Exp. Zool. B Mol. Dev. Evol. 306:575-588.

Sempere LF, Freemantle S, Pitha-Rowe I, Moss E, Dmitrovsky E, Ambros V. 2004. Expression profiling of mammalian microRNAs uncovers a subset of brain-expressed microRNAs with possible roles in murine and human neuronal differentiation. Genome Biol. 5:R13.

Smith O, Clapham A, Rose P, Liu Y, Wang J, Allaby RG. 2014. A complete ancient RNA genome: identification, reconstruction and evolutionary history of archaeological Barley Stripe Mosaic Virus. Sci. Rep. 4:4003.

Smith O, Dunshea G, Sinding M-HS, Fedorov S, Germonpre M, Bocherens H, Gilbert MTP. 2019. Ancient RNA from Late Pleistocene permafrost and historical canids shows tissuespecific transcriptome survival. PLoS Biol. 17:e3000166.

Smith O, Palmer SA, Clapham AJ, Rose P, Liu Y, Wang J, Allaby RG. 2017. Small RNA Activity in Archeological Barley Shows Novel Germination Inhibition in Response to Environment. Mol. Biol. Evol. 34:2555-2562.

Tarver JE, Sperling EA, Nailor A, Heimberg AM, Robinson JM, King BL, Pisani D, Donoghue PCJ, Peterson KJ. 2013. miRNAs: small genes with big potential in metazoan phylogenetics. Mol. Biol. Evol. 30:2369-2382.

Teta M, Choi YS, Okegbe T, Wong G, Tam OH, Chong MMW, Seykora JT, Nagy A, Littman DR, Andl T, et al. 2012. Inducible deletion of epidermal Dicer and Drosha reveals multiple functions for miRNAs in postnatal skin. Development 139:1405-1416.

Tuomisto S, Karhunen PJ, Vuento R, Aittoniemi J, Pessi T. 2013. Evaluation of Postmortem Bacterial Migration Using Culturing and Real-Time Quantitative PCR. Journal of Forensic Sciences [Internet] 58:910-916. Available from: http://dx.doi.org/10.1111/15564029.12124

Venanzi FM, Rollo F. 1990. Mummy RNA lasts longer. Nature 343:25-26. 


\section{Supplementary Figures}

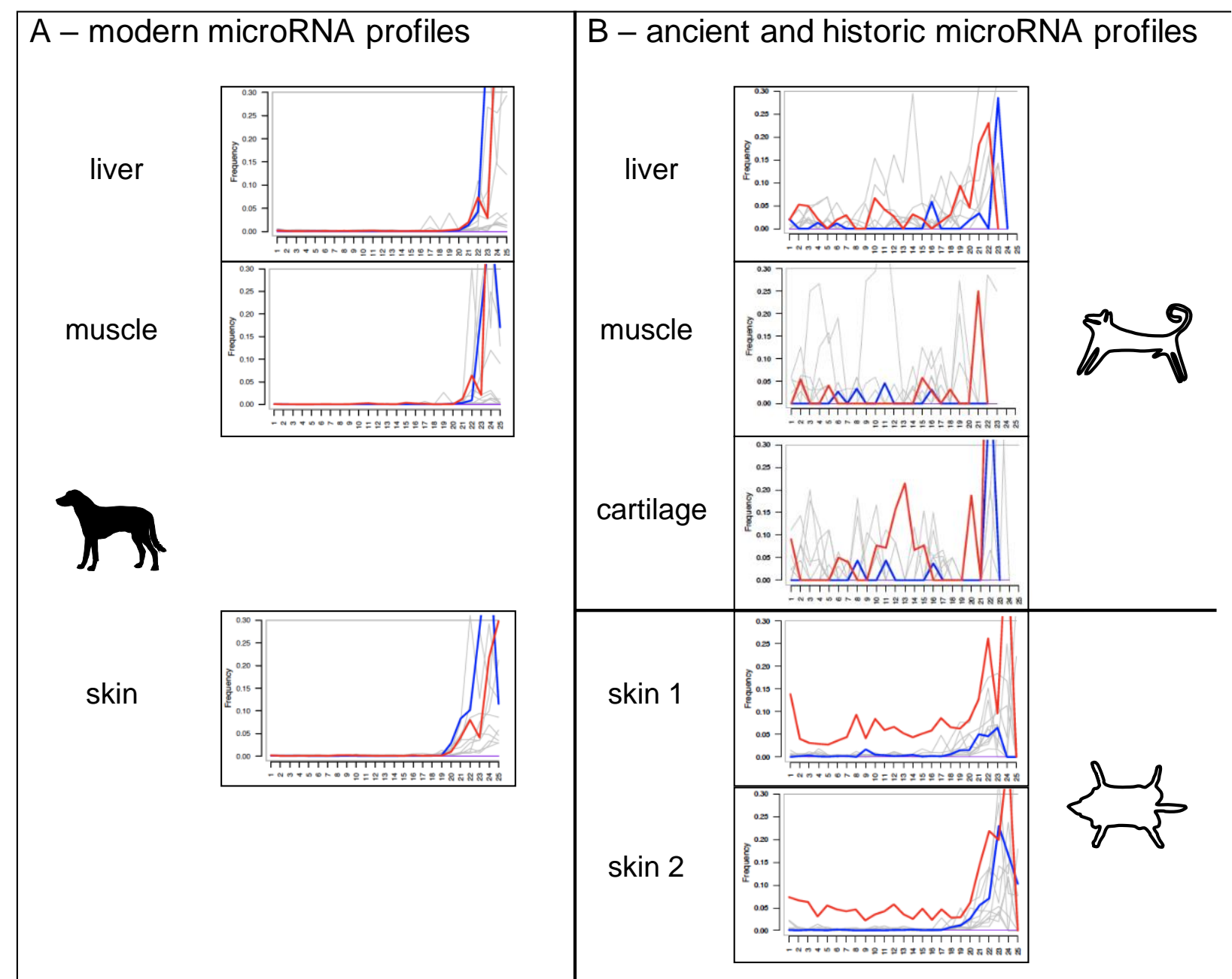

Supplementary Figure 1: mapDamage profiles of A) modern and B) ancient and historic canid tissue samples to canid microRNA loci. Red lines show $\mathrm{C}>\mathrm{U}$ transitions, while blue lines show $\mathrm{G}>\mathrm{A}$ transitions. Note that the observation of 3' non-templated nucleotides, in particular uridylations, is a hallmark of microRNAs. For the historic samples, overall conversion rate appears to be comparable to those described for ancient mRNA. However, for microRNAs, deaminase events appear to be the most frequent conversion type by far. For the ancient samples, nucleotide conversion rates are high and do not appear to be highly enriched for deaminase events. However, given the relatively low number of microRNA reads detected, we are reluctant to make strong conclusions at this point. 

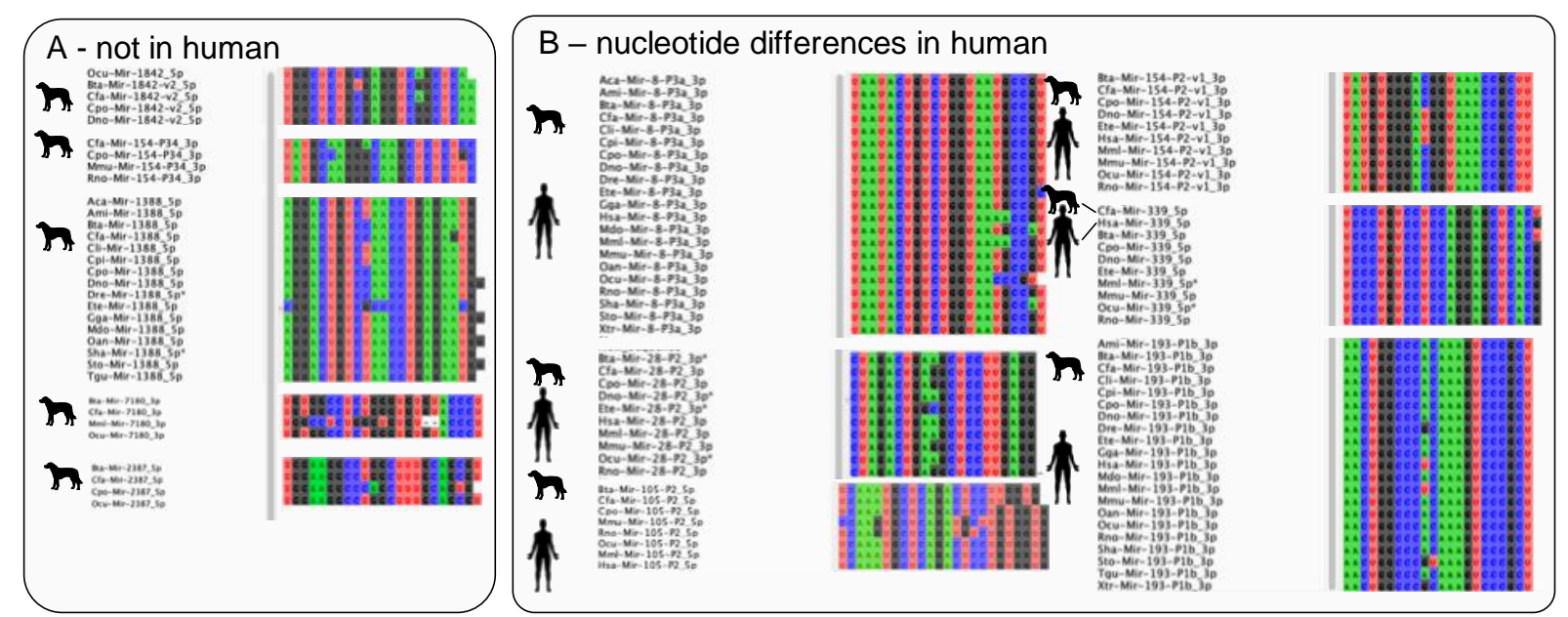

Supplementary Figure 2: Conserved microRNAs that are taxonomically informative because they are either A) not found in human or B) found in human and showing nucleotide differences to at least one other MirGeneDB organism or human, respectively.
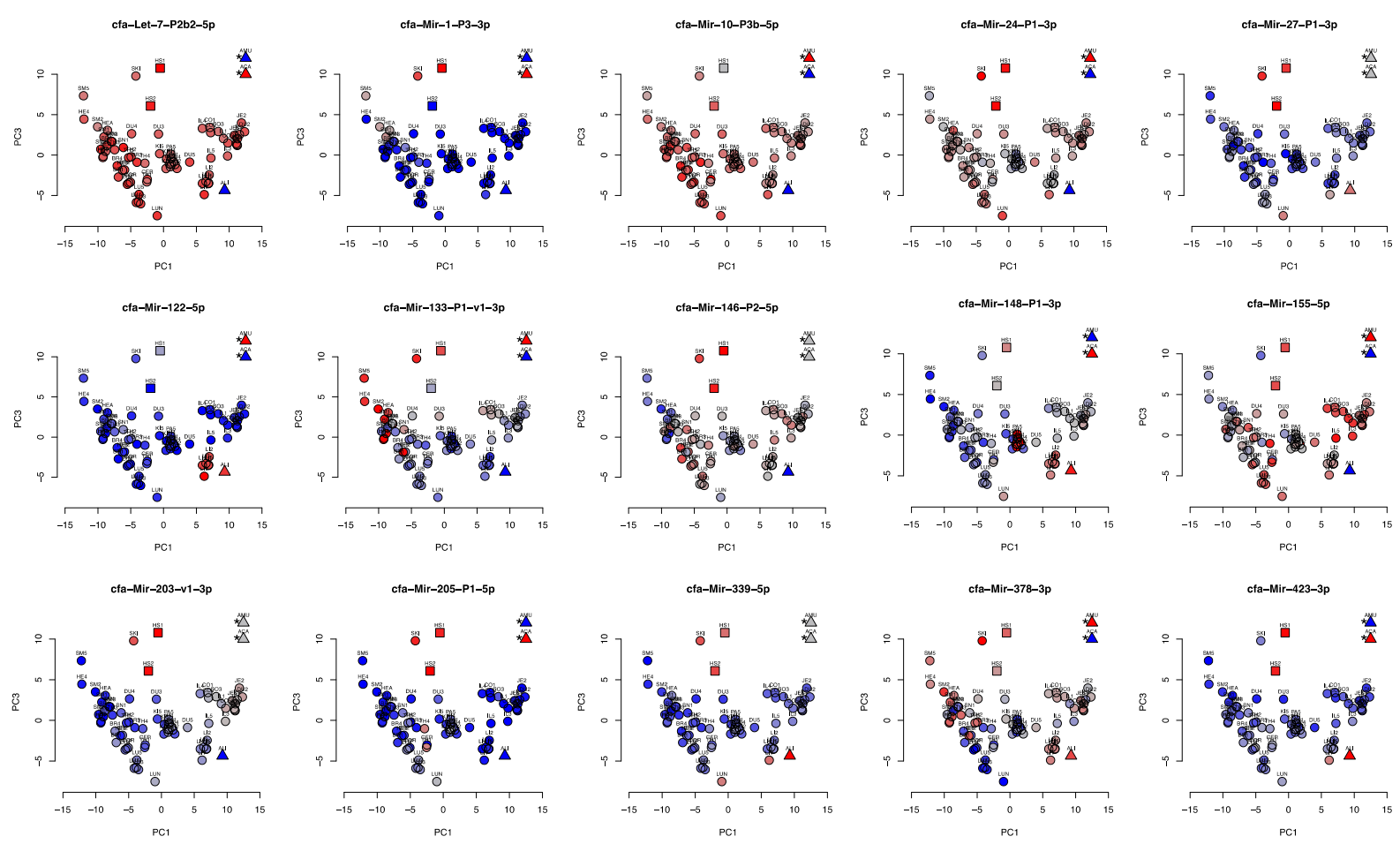

Supplementary Figure 3: Cell type- and Tissue-Specificity of selected microRNAs across 69, 3 ancient and 2 historic samples. The PCA plot from Figure 2 was re-used to depict the color-coded detection of 15 selected microRNAs (blue - low, red -high), note that ancient cartilage and muscle samples were included to show expression of microRNAs. Thus, their relative position does not depict their distance to the other samples. 
Supplementary Table 1 - Summarized gene ontology enrichments of targets of 1a ancient liver specific microRNAs, $1 \mathrm{~b}$ ancient muscle specific microRNAs, 1c ancient cartilage specific microRNA, and 1d historic skin specific microRNA

Supplementary Table 1a - Summarized gene ontology enrichments of targets of ancient liver specific microRNA

\begin{tabular}{|c|c|}
\hline microRNA & Enriched terms \\
\hline \multirow[t]{2}{*}{ cfa-Mir-122-5p } & $\begin{array}{l}\text { Carbohydrate metabolism (GO:0005996, 0005975, 0019318, ...) } \\
\text { Response to Starvation (GO:0042594, 0042149, 0009267) } \\
\text { Growth factors (GO:1990090, 1990089, 0070848, ..) }\end{array}$ \\
\hline & Transcriptional regulation (GO:0000978, 0001067, 0000977, ...) \\
\hline \multirow[t]{2}{*}{ cfa-Mir-339-5p } & $\begin{array}{l}\text { Estrogen and androgen metabolism (GO:0006703, 0008209, 0008210, } \\
\ldots \text { ) } \\
\text { Fatty acid and CoA biosynthesis (GO:0046949, 0035337, 0035384, ..) }\end{array}$ \\
\hline & Enzymatic activity (GO:0047025, 0047035, 0003857, ...) \\
\hline \multirow[t]{3}{*}{ cfa-Mir-423-3p } & $\begin{array}{l}\text { Protein deglycosylation (GO: } 1904380,0036507,0036508, \ldots) \\
\text { Misfolded protein reaction (GO:0071712, } 0071218,0051788, \ldots)\end{array}$ \\
\hline & Transcriptional regulation (GO:0043565, 0003682, 1990837, ...) \\
\hline & Hippo signaling pathway (hsa04390) \\
\hline
\end{tabular}

Supplementary Table 1b - Summarized gene ontology enrichments of targets of ancient muscle specific microRNA

\begin{tabular}{|l|l|}
\hline microRNA & Enriched terms \\
\hline cfa-Mir-155-5p & $\begin{array}{l}\text { Regulation of transcription }(\mathrm{GO}: 1903506,0006355,2001141, \ldots) \\
\text { Protein modification }(\mathrm{GO}: 0006464,0036211)\end{array}$ \\
\cline { 2 - 2 } & Transcriptional regulation $(\mathrm{GO}: 0003690,0000977,0001012, \ldots)$ \\
\hline
\end{tabular}




\begin{tabular}{|c|c|}
\hline & $\begin{array}{l}\text { Acute myeloid leukemia (hsa05221) } \\
\text { Osteoclast differentiation (hsa04380) }\end{array}$ \\
\hline \multirow[t]{2}{*}{$\begin{array}{l}\text { cfa-Mir-378-3p } \\
\text { (also high in liver) }\end{array}$} & $\begin{array}{l}\text { Regulation of signaling (GO:0043405, } 0010646,0007267, \ldots) \\
\text { Protein modification (GO:0006464, 0036211) } \\
\text { Regulation of cardiac muscle / cardiocytes (GO:2000726, 1905208) }\end{array}$ \\
\hline & Transcriptional regulation (GO:0044212, 0001067, 0043565, ...) \\
\hline \multirow[t]{2}{*}{ cfa-Mir-10-P3b-5p } & $\begin{array}{l}\text { Carbohydrate and fat metabolism (GO:0009311, 0009313,0006665, ..) } \\
\text { Epithelium / cell polarity related (GO:0001738, 0001736, 0007164, ..) } \\
\text { Regulation of hematopoietic cell types (GO:1901532, GO:1902036, } \\
\text { 0060218) }\end{array}$ \\
\hline & $\begin{array}{l}\text { Transcriptional regulation (GO:0000987, 0000977, 0001012, ..) } \\
\text { Enzymatic activity (GO:0004308, 0016997, 0052794, ..) }\end{array}$ \\
\hline \multirow[t]{3}{*}{ cfa-Mir-133-3p } & $\begin{array}{l}\text { Transcriptional regulation (GO:1903508, } 1902680,0051254, \ldots) \\
\text { Regulation of actin filament-based process (GO:0032970) } \\
\text { Neurotransmitter / Synapse (GO:0007269, 0099643) }\end{array}$ \\
\hline & $\begin{array}{l}\text { Divalent inorganic cation transmembrane transporter activity } \\
\text { (GO:0072509) } \\
\text { Cell adhesion (GO:0050839) } \\
\text { GABA receptor binding (GO:0050811) }\end{array}$ \\
\hline & Synaptic vesicle cycle (hsa04721) \\
\hline
\end{tabular}

Supplementary Table 1c - Summarized gene ontology enrichments of targets of ancient cartilage specific microRNA

\begin{tabular}{|l|l|}
\hline microRNA & Enriched terms \\
\hline $\begin{array}{l}\text { cfa-Mir-205-P1- } \\
\mathrm{p}\end{array}$ & Regulation of signaling $(\mathrm{GO}: 0023051,0010646,0023056, \ldots)$ \\
\cline { 2 - 2 } & $\begin{array}{l}\text { Transcriptional regulation }(\mathrm{GO}: 1990837,0003690,0043565, \ldots) \\
\text { Enzyme activity (GO:0004308, 0016997, 0052794, ...) } \\
\text { Platelet-derived growth factor receptor }(\mathrm{GO}: 0005161)\end{array}$ \\
\cline { 2 - 2 } & Hippo signaling pathway (hsa04390, hsa04392) \\
\hline
\end{tabular}




\begin{tabular}{|c|c|}
\hline \multirow[t]{3}{*}{$\begin{array}{l}\text { cfa-Let-7-P2b2- } \\
5 \mathrm{p}\end{array}$} & $\begin{array}{l}\text { Transcriptional regulation (GO:0006357, 0006366) } \\
\text { Appendage and limp development (GO:0030326, 0035113, 0035107, ..) }\end{array}$ \\
\hline & $\begin{array}{l}\text { Transcriptional regulation (GO:0003700, 0000981,0140110, ...) } \\
\text { Post-transcriptional regulation (GO:0030371, 0000900) } \\
\text { CCR1 chemokine receptor binding (GO:0031726) }\end{array}$ \\
\hline & Cancer (hsa05206, hsa05205, hsa05214) \\
\hline \multirow[t]{2}{*}{ cfa-Mir-1-P3-3p } & Chromatin modification (GO:0018027, 0051567, 0016570, ...) \\
\hline & $\begin{array}{l}\text { Chromatin modification (GO:0046974, 0046976, 0018024, ...) } \\
\text { Transcriptional regulation (GO:1990841, 0070742, 0140110, ...) } \\
\text { Cytoskeletal protein binding (GO:0008092) }\end{array}$ \\
\hline cfa-Mir-423-3p & cfa-Mir-155-5p see above \\
\hline
\end{tabular}

Supplementary Table 1d - Summarized gene ontology enrichments of targets of historic skin specific microRNA

\begin{tabular}{|c|c|}
\hline microRNA & Enriched terms \\
\hline \multirow[t]{3}{*}{$\begin{array}{l}\text { cfa-Mir-203-v1- } \\
3 p \\
\text { (cfa-Mir-203-v2- } \\
3 p \text { is similar) }\end{array}$} & $\begin{array}{l}\text { Response to stimulus (GO:0071495, 0009719) } \\
\text { Epithelium and blood vessel development (GO:0060429, 0001568) } \\
\text { Positive regulation of smooth muscle cell migration (GO:0014911) } \\
\text { Cell death (GO:0008219, 0012501, 0006915) }\end{array}$ \\
\hline & $\begin{array}{l}\text { Transcriptional regulation (GO:0070888, 0000981, 0003700, ..) } \\
\text { Growth factor receptors (GO:0008083, 0030618) }\end{array}$ \\
\hline & $\begin{array}{l}\text { Synapse (hsa04727) } \\
\text { Growth factor (hsa04350, hsa04935, hsa01521) }\end{array}$ \\
\hline \multirow[t]{2}{*}{$\begin{array}{l}\text { cfa-Mir-146-P2- } \\
5 \mathrm{p}\end{array}$} & $\begin{array}{l}\text { Ectodermal development (GO:0007439, 0048611, 0010668, ...) } \\
\text { Transcriptional regulation (GO:0051254, 0045893, 1903508, ...) } \\
\text { Appendage and limp development (GO:0030326, 0035113) }\end{array}$ \\
\hline & $\begin{array}{l}\text { Transcriptional regulation (GO:0001228, 0140110, 0003700, ...) } \\
\text { Synapses (GO:0000149, 0019905) }\end{array}$ \\
\hline
\end{tabular}


bioRxiv preprint doi: https://doi.org/10.1101/2019.12.16.877761; this version posted December 17, 2019. The copyright holder for this preprint (which was not certified by peer review) is the author/funder. All rights reserved. No reuse allowed without permission.

\begin{tabular}{|l|l|}
\hline cfa-Mir-27-P1-3p & Protein modification (GO:0006464, 0036211) \\
\cline { 2 - 3 } & $\begin{array}{l}\text { Transcriptional regulation (GO:0001228, 0140110, 0003700) } \\
\text { Ion binding (GO:0043167, 0046872, 0043169) }\end{array}$ \\
\hline cfa-Mir-205-P1-5p and cfa-Mir-378-3p see above \\
\hline
\end{tabular}

